\title{
GPIAG/IPCRG News
}

\section{GPIAG News}

Appraisal Service for GPwSIs in respiratory
medicine

The General Practice Airways Group (GPIAG) recently held an appraisal training weekend for a small group of members who are able to offer an appraisal service for general practitioners (GPs) with a special interest in respiratory medicine.

Primary Care Organisations or individual GPwSls who are interested in using this service should contact the GPIAG secretariat on info@gpiag.org or telephone 01461600639.

Influencing Respiratory $\mathrm{Fol}$ cy âder Practice

The GPI/ 0 sim itfed ts response to thi review of the Quality and Cutcomes Franicivis of the GMS contract at the end of May. Following an extensive consultation process with members via the e-alert system, respiratory indicators were proposed in asthma, COPD and rhinitis as follows:

- Asthma - Peak flow variability in diagnosis

- Asthma - Checking inhaler technique

- Asthma - RCP 3 questions for monitoring control

- Asthma - 'At risk' register for severe or brittle asthma

- Asthma - Personal asthma action plans

- COPD - MRC dyspnoea score to monitor severity

- Asthma and Rhinitis - Maintaining a register of patients with rhinitis

The two indicators which received universal approval were self management plans for asthma and the MRC dyspnoea score to monitor COPD. Where a consensus was not possible we have tried to represent the majority view and indicated alternative perspectives under the section for 'professional support'.
The GPIAG response can be viewed in full on www.gpiag.org

New GPIAG Asthma Assessment Tool Supports Need for Greater Emphasis on Role of Allergy

The GPIAG has called for allergy and allergic symptoms to be given increased emphasis in the overall diagnosis and management of asthma. The group launched a new asthma assessment tool aimed at improving asting management and control vich Jor the first time, takes into Accunt the potential impact of allergic symptoms.

The rita) irom the GPIAG comes amid growing conicern among healthcare professionals that allergy is a neglected area of the NHS - a concern shared by the GPIAG. According to a report by the House of Commons Health Committee, even though allergic disease affects around $30 \%$ of the adult population and $40 \%$ of children in the UK, there is approximately only one specialist consultant per two million people, resulting in a considerable gap between the need for allergy services and their provision. ${ }^{1}$ This is emphasised by the fact that there are very few specialist allergy clinics and in addition, the great majority of GPs receive little allergy training as students and no extra postgraduate training. 1

The GPIAG, together with Allergy UK, and supported by an unrestricted educational grant from Merck Sharp \& Dohme Ltd, has developed a simple asthma status measure and patient self-assessment checklist to provide support for GPs during patients' asthma reviews and to raise awareness amongst asthma patients in the UK who suffer with both asthma and coexisting allergic rhinitis. The GP checklist is 
available via the GPIAG website www.gpiag.org/ news/gp_diagnostic_tool.pdf

\section{References:}

1. House of Commons Health Committee. The Provision of Allergy Services, Sixth Report of Session 2003-04, vol I and vol II, October 2004. http://www.bsaci.org/open/pdf/provision_of _ allergy_services.pdf

\section{E-Alert System}

The email alert system allows the GPIAG to provide rapid updates on its activities, and to put new information on the website on respiratory matters of interest to primary care health professionals. If you are not already a subscriber, please do join by visiting www.gpiag.org/mail/ subscribe/php.

Please remember to let us know if you change your email address too.

\section{Getting Involved}

If you have questions about the work of the GPIAG or how you can get more actively involved, please contact us via info@gpiag.org or see http://www.gpiag.org/about/committee.php for General Committee members contact details

\section{IPCRG News}

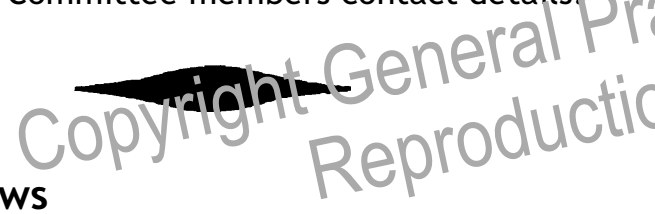

It gives us great pleasure to invite you to the 3rd IPCRG World Conference which will take place in Oslo, Norway, June $8-11,2006$. The venue is the excellent Radisson SAS Plaza Hotel in the centre of Oslo close to the famous Karl Johan Street. Registration and call for abstracts is now open, and closing date for submission of abstracts is December 15th 2005. The conference website will contain all information and links to the online submission; http://www.theipcrg.org/oslo2006. We welcome you all to Oslo to enjoy the scientific, cultural and social content of this 3rd World conference meeting.

The conference will provide an interdisciplinary meeting place for general practitioners (GPs), nurses and other health professionals with an interest in respiratory medicine. The conference is accredited for 30 points from the Norwegian Medical Association. CME accreditation has been applied for.

Anders Ostrem

IPCRG President

\section{Healthcare Commission - Forthcoming Improvement Review of COPD}

The UK Healthcare Commission's role is to promote improvement in the quality of healthcare across England and Wales. It recently launched its new system for assessing the quality of healthcare services in England. This system monitors NHS organisations' performance against Department of Health standards as well as providing a series of improvement reviews, which assess the way NHS organisations are making and sustaining progress.

In 2005-06 the Healthcare Commission will be working on an improvement review of chronic obstructive pulmonary disease (COPD). Over the coming year, the Commission's project team will be working with clinical professionals and users of services to identify key themes in the management of COPD. The team is particularly interested in the evidence to suggest that better 'case management' of COPD patients in primary care will reduce the need for hospital intervention. This review will include a focus on the case management of COPD patients who require intensive, specialist care and are frequently admitted to hospita'. It will also encompass elements of $/ \mathrm{GCL}$ g diciance, and primary care activities n recation to COPD.

aCthe siudy team vill be attending the GPIAG Conferende id 8tic lealy 2005 in Crewe, and will have a stand in the Charities section. The study team is keen to consult widely about its proposed work, and to involve primary care clinicians in its development. If you would like more information about the review, or you would like to draw attention to notable practice, please contact a member of the study team;

Bev Fitzsimons;

beverley.fitzsimons@healthcarecommission.org.uk

Ann Goodridge;

ann.goodridge@healthcarecommission.org.uk

If you would like more information about the Healthcare Commission, please visit our website www.healthcarecommission.org.uk

\section{NRTC News}

\section{Chronic Disease Management Diploma launched by new professional Alliance}

Three of the UK's leading professional organisations from the field of diabetes (Warwick Diabetes Care), cardiovascular disease (Heartsave) and respiratory disease (National Respiratory Training Centre) have collaborated in the development of a new, innovative Chronic Disease Management Diploma, which is launched today. 
It is specifically designed to be relevant to all health professionals, particularly nurses working in primary care settings

The Diploma programme takes an holistic approach to the management of long term conditions, as well as providing a focus on individual chronic diseases. Over 17 million people in the UK currently live with a long-term condition. The Department of Health has recognised that good management of these long-term conditions offers real opportunities for improvements in patient care and service quality alongside a reduction in costs. This Diploma is designed to reflect these Government priorities.

The aim of the new Alliance in developing this Diploma is to provide cohesive education that will help health professionals to gain the knowledge and skills that will enable them to set up and run effective chronic disease management clinics, and to support people with more complex needs.

For more information about the Alliance or Diploma Programme call Liz Bryant on 01926493313 or email l.bryant@nrtc.org.uk

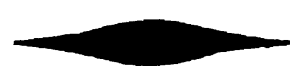

\section{RETC News}

\section{MSc in Respiratory Disease Mina selnent}

This multidisciplinary course will enabll=0 practitioners of Exic at vario us stages Co O.he inSc programme with a named aviaic. Un completion of the first three modules (or completion of two and APEL towards one) students may exit with a Post Graduate Certificate in Respiratory Disease management. Similarly on completion (or APEL) of modules amounting to an additional 60 credits, student may exit with a Post Graduate Diploma. A total of 180 credits, including compulsory modules such as the dissertation, are required for the award of MSc.

There are a range of module options which enable the student to identify modules which are most relevant to their area of clinical practice and to focus on the subject matter as it applies to their own role. Modules include:

Post Graduate Certificate level (60 credits): Interpretation of respiratory investigations; Respiratory investigations and diagnosis; Research.

Post Graduate Diploma (60 credits from the following modules): Ethical issues (10 credits); Obstructive disorders (20); Cancer (20); Respiratory failure (20); Communication and education (10); Paediatrics (20).

MSc Award: Dissertation (60)

Students may be able to APEL against the award.
For more detailed information on the MSC programme and course costs please contact Debbie Soady on 01515292598.

The programme is subject to validation in September.

The RETC is once again running a series of multidisciplinary meetings entitled

A Breath of Fresh Air:

$28^{\text {th }}$ September 2005 Fielder Centre,

Hertfordshire

$6^{\text {th }}$ October 2005

Marriott Hotel, Gosforth Park

$19^{\text {th }}$ October 2005

Templeton Hotel, Templepatrick

$3^{\text {rd }}$ November 2005

Stirling Management Centre

CPD approval has been granted for all meetings

For further information on any of these contact: Tracey Haigh on 01515296229 or tracey@respiratoryetc.com

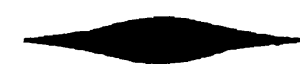

The European Forumifoldinary Care a boost for pribialy cüre in Europe

inflp it 28, the European Forum for Primary Care was launshed in the European Parliament in Brussets

The vision of the Forum is as follows:

Strong primary care (PC) produces better health outcomes with lower costs. That is the briefest summary of available scientific evidence. By promoting strong PC the population's health can be improved. Strong PC does not occur spontaneously. It requires appropriate conditions in health care systems and in practice to make PC providers able and willing to take responsibility for the health of the population under their care. Everywhere in Europe the process of strengthening PC is ongoing. There is a strong need to collect and share information about what structures and strategies matter. The developments in the European Union provide both challenges and opportunities to the further development of Primary Care. For these reasons the European Forum for Primary Care was created. It intends to connect policymakers and practitioners, to support practitioners, and to stimulate research in Primary Care.

The Forum will monitor health related policies in the European Union and offer its reflections and vision. It will also monitor the development of Primary Care in the countries of Europe, publish position papers, and offer facilities for exchange through events and its website. The latter was operational from April 28th 2005 and will gradually 
be filled with contributions from its members. Website address: www.euprimarycare.org

Several networks already exist in Europe, in which researchers and practitioners in Primary Care exchange information, such as WONCA and EURACT. The Forum will collaborate closely with these networks and support them. Duplication will be avoided.

The Forum has been initiated by policymakers, practitioners and researchers in Primary Care from seven countries: UK, Belgium, the Netherlands, Estonia, Denmark, Italy and France. This multidisciplinary group (nurses, general practitioners, public health experts) will be extended to include other countries and other disciplines and thereby the steering committee of the Forum will evolve. Individuals and organisations throughout Europe, including non-EU member states, are welcome to take up membership of the Forum, which will entitle them to certain benefits.
During the launch, the Forum was welcomed by Mrs Anne van Lancker, MEP. She stressed the timeliness of the creation of the Forum in view of European developments. Mrs Ria von Bönninghausen, president of the Standing Committee of Nurses (PCN) and Dr Igor Svab, president of WONCA Europe, emphasised the fact that the Forum complements the activities of WONCA.

Prof Jan de Maeseneer, Ghent University, is chairman of the steering committee of the Forum. The Forum secretariat is based in the Netherlands Institute for Care and Welfare in Utrecht, The Netherlands.

For contact and further information please check the website or contact info@euprimarycare.org. You can call Mrs Brigitte Domittner tel + 31302306 413 or Mr Pim de Graaf +316 51550492 for additional information.

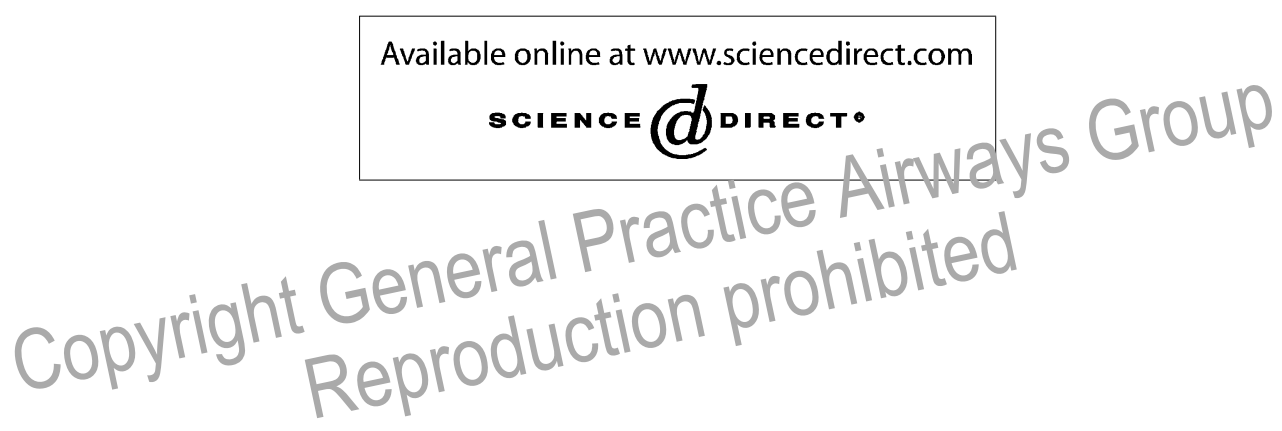

Available online at http://www.thepcrj.com 